\title{
A surrogate-assisted approach for the optimal synthesis of refinery hydrogen networks - Supporting information
}

Shihui Wang, ${ }^{\dagger}$ Li Zhou, ${ }^{*}{ }^{\dagger}$ Xu $\mathrm{Ji}_{,}^{\dagger}{ }^{\text {Iftekhar A. Karimi, }}{ }^{\ddagger} \mathrm{Ge} \mathrm{He},{ }^{\dagger}$ Yagu Dang, $^{\dagger}$ and Xia Xuף

$\dagger$ Department of Chemical Engineering, Sichuan University, Chengdu 610065, PR China. $\ddagger$ Department of Chemical \& Biomolecular Engineering, National University of Singapore, 117585, Singapore

\Chengdu Branch of Data Communication of Civil Aviation Co., Ltd., Chengdu 610042, PR China.

E-mail: chezli@scu.edu.cn

Phone: +8615228867167

\section{Accuracy measures}

To test the constructed models comprehensively, a number of measures are used including $R^{2}$ (coefficient of determination), ${ }^{1]} R M S E$ (root mean square error) ${ }^{[2}$ and residual plot. The indices are defined as follows.

$$
\begin{gathered}
R^{2}=1-\frac{\sum_{n=1}^{N}\left(y^{(n)}-f^{(n)}\right)^{2}}{\sum_{n=1}^{N}\left(y^{(n)}-\bar{y}\right)^{2}} \\
R M S E=\sqrt{\frac{\sum_{n=1}^{N}\left(y^{(n)}-f^{(n)}\right)^{2}}{N}}
\end{gathered}
$$




$$
\epsilon^{(n)}=y^{(n)}-f^{(n)}
$$

where $y^{(n)}$ is the $n$th data point, $f^{(n)}$ is a $n$th model predicted value, $\bar{y}$ is the empirical mean of data points, $\epsilon^{(n)}$ refers to residual for $n$th data point and $n=1,2, \cdots, N$.

\section{Empirical models of hydroprocessing reactors}

The formulations of sulphur removal and light hydrocarbons produced in the reactor are given by Eq. 4 and Eqs. 56, respectively. Equation 7 describes the formation of hydrogen sulfide.

$$
Y_{S, j}^{r o} \times 10000=\left(Y_{S, j}^{r i} \times 10000\right)^{\beta_{j}} \times \exp \left\{\left(\frac{-k_{j}}{K \times Y_{3+R, j}^{r i} \times 10000}\right)\left(\frac{\alpha_{j} P_{\mathrm{H}_{2}, j}^{r i}}{L H S V_{j}}\right)\right\} \quad \forall j
$$

where $Y_{S, j}^{r o}$ and $Y_{S, j}^{r i}$ represent sulphur content of the feed and the product, $k_{j}$ is the rate constant of HDS reaction, $K$ is the $3+$ ring aromatic inhibition constant, $Y_{3+R, j}^{r i}$ is inlet $3+$ ring core aromatic content, $P_{\mathrm{H}_{2}, j}^{r i}$ is the partial pressure of hydrogen and $L H S V_{j}$ is liquid hourly space velocity. $\alpha_{j}$ and $\beta_{j}$ are correction parameters.

$$
\begin{gathered}
F_{C i, j}^{r o}=\gamma_{C i, j} \times \operatorname{cov}_{j} \times\left\{k_{0 C i, j}-\exp \left[\left(\frac{-E_{a C i, j}}{R T_{j}^{r}}\right)\left(\frac{P_{j}^{r} \times \varepsilon}{L H S V_{j}}\right)\right]\right\} \quad \forall j, C i=\{C 1, C 2, \cdots, C 5\} \\
\operatorname{cov}_{j}=1-\left(\frac{Y_{S, j}^{r o}}{Y_{S, j}^{r i}}\right) \quad \forall j \\
F_{\mathrm{H}_{2} \mathrm{~S}, j}^{r o}=\frac{M W_{\mathrm{H}_{2} \mathrm{~S}}}{M W_{S}} \times\left[\left(Y_{S, j}^{r i} \times F_{o i l, j}^{r i}\right)-\left(Y_{S, j}^{r o} \times F_{L P, j}^{r o}\right)\right] \quad \forall j
\end{gathered}
$$

where $F_{C i, j}^{r o}$ is the mass flowrate of light hydrocarbons formed, $\gamma_{C i, j}$ is the yield coefficient of light hydrocarbons formed and $\operatorname{cov}_{j}$ is the sulphur conversion, $k_{0 C i, j}$ is the temperature dependence parameter, $E_{a C i, j}$ is the activation energy, $T_{j}^{r}$ and $P_{j}^{r}$ represent the temperature and the pressure of the reactor, $\varepsilon$ is a pressure dependent term, $F_{\mathrm{H}_{2} \mathrm{~S}, j}^{r o}$ is the mass flowrate of $\mathrm{H}_{2} \mathrm{~S}$ formed, $M W_{\mathrm{H}_{2} \mathrm{~S}}$ and $M W_{S}$ represent the molecular weight of $\mathrm{H}_{2} \mathrm{~S}$ and $\mathrm{S}, F_{\text {oil }, j}^{r i}$ and 
$F_{L P, j}^{r o}$ stand for the mass flowrate of the feed oil flow and the liquid product respectively. The parameters as shown in Table S1 can be estimated by using a generalised reduced gradient method.

Table S1: Parameters for the light hydrocarbons formed models

\begin{tabular}{cccc}
\hline Light hydrocarbons/Parameters & $\gamma(\mathrm{t} / \mathrm{h})$ & $k_{0}$ & $E_{a}(\mathrm{~kJ} / \mathrm{kmol})$ \\
\hline C1 & 4.0066 & 0.1550 & 365.3463 \\
C2 & 8.5276 & 0.0994 & 452.7053 \\
C3 & 25.2526 & 0.1266 & 407.6503 \\
C4 & 28.8097 & 0.1153 & 424.7202 \\
C5 & 12.4948 & 0.4589 & 152.6564 \\
\hline
\end{tabular}

\section{Relative data for the case study}

The case study is taken from Jia and Zhang, ${ }^{3}$ which consists of two hydrogen producers and four hydrogen consumers. The hydrogen producers are $\mathrm{H}_{2}$ plant and CCR. The hydrogen consumers are naphtha hydrotreating unit (NHT), cracked naphtha hydrotreating unit (CNHT), diesel hydrotreating unit (DHT) and vacuum gas oil hydrocracking unit (VGOHC).

The operation temperature and pressure for the base case is given in Table $\mathrm{S} 2$ and the component concentrations of liquid feedstock are listed in Table S3.

Table S2: Operation conditions of the reactors and flash units for the base case.

\begin{tabular}{cccccc}
\hline Reactors & T $(\mathrm{K})$ & P (bar) & Flash units & T (K) & P (bar) \\
\hline NHT & 623 & 60 & NHT & 323 & 18 \\
CNHT & 653 & 65 & CNHT & 323 & 20 \\
DHT & 633 & 60 & DHT & 323 & 20 \\
VGOHC & 653 & 52.96 & VGOHC & 323 & 160 \\
\hline
\end{tabular}


Table S3: Detailed liquid feedstock data for the case study

\begin{tabular}{|c|c|c|c|c|}
\hline Hydroprocessors & NHT & CNHT & DHT & VGOHC \\
\hline Feed flowrate $(\mathrm{t} / \mathrm{h})$ & 175.041 & 75.886 & 337.563 & 260.004 \\
\hline \multicolumn{5}{|c|}{ Composition (mass fraction) } \\
\hline $\mathrm{H}_{2}$ & 0.0000 & 0.0000 & 0.0000 & 0.0000 \\
\hline $\mathrm{C} 1$ & 0.0000 & 0.0000 & 0.0000 & 0.0000 \\
\hline $\mathrm{C} 2$ & 0.0000 & 0.0000 & 0.0000 & 0.0000 \\
\hline $\mathrm{C} 3$ & 0.0000 & 0.0000 & 0.0000 & 0.0000 \\
\hline $\mathrm{C} 4$ & 0.0000 & 0.0000 & 0.0000 & 0.0000 \\
\hline C5 & 0.0000 & 0.0000 & 0.0000 & 0.0000 \\
\hline $\mathrm{H}_{2} \mathrm{~S}$ & 0.0000 & 0.0000 & 0.0000 & 0.0000 \\
\hline PC1-NHT & 0.1627 & 0.0000 & 0.0001 & 0.0000 \\
\hline PC2-NHT & 0.2051 & 0.0000 & 0.0002 & 0.0000 \\
\hline PC3-NHT & 0.2207 & 0.0000 & 0.0002 & 0.0000 \\
\hline PC4-NHT & 0.2686 & 0.0000 & 0.0003 & 0.0000 \\
\hline PC5-NHT & 0.1429 & 0.0000 & 0.0002 & 0.0000 \\
\hline $\mathrm{PC} 1-\mathrm{CNI}$ & 0.0000 & 0.0916 & 0.0000 & 0.0000 \\
\hline $\mathrm{PC} 2-\mathrm{CNH}$ & 0.0000 & 0.1675 & 0.0000 & 0.0000 \\
\hline PC3-CNHT & 0.0000 & 0.2422 & 0.0000 & 0.0000 \\
\hline PC4-CNHT & 0.0000 & 0.2031 & 0.0000 & 0.0000 \\
\hline PC5-CNHT & 0.0000 & 0.2957 & 0.0000 & 0.0000 \\
\hline PC1-DHT & 0.0000 & 0.0000 & 0.0745 & 0.0000 \\
\hline PC2-DHT & 0.0000 & 0.0000 & 0.1743 & 0.0000 \\
\hline PC3-DHT & 0.0000 & 0.0000 & 0.2630 & 0.0000 \\
\hline PC4-DHT & 0.0000 & 0.0000 & 0.3502 & 0.0000 \\
\hline PC5-D & 0.0000 & 0.00 & 0.1371 & 0.0000 \\
\hline PC1-VGOHC & 0.0000 & 0.0000 & 0.0000 & 0.0062 \\
\hline PC2-VGOHC & 0.0000 & 0.0000 & 0.0000 & 0.0133 \\
\hline PC3-VGOHC & 0.0000 & 0.0000 & 0.0000 & 0.0281 \\
\hline PC4-VGOHC & 0.0000 & 0.0000 & 0.0000 & 0.0192 \\
\hline PC5-VGOHC & 0.0000 & 0.0000 & 0.0000 & 0.0140 \\
\hline PC6-VGOHC & 0.0000 & 0.0000 & 0.0000 & 0.0213 \\
\hline PC7-VGOHC & 0.0000 & 0.0000 & 0.0000 & 0.0358 \\
\hline PC8-VGOHC & 0.0000 & 0.0000 & 0.0000 & 0.0825 \\
\hline PC9-VGOHC & 0.0000 & 0.0000 & 0.0000 & 0.0738 \\
\hline PC10-VGOHC & 0.0000 & 0.0000 & 0.0000 & 0.0349 \\
\hline PC11-VGOHC & 0.0000 & 0.0000 & 0.0000 & 0.0756 \\
\hline PC12-VGOHC & 0.0000 & 0.0000 & 0.0000 & 0.1242 \\
\hline PC13-VGOHC & 0.0000 & 0.0000 & 0.0000 & 0.1872 \\
\hline PC14-VGOHC & 0.0000 & 0.0000 & 0.0000 & 0.1831 \\
\hline PC15-VGOHC & 0.0000 & 0.0000 & 0.0000 & 0.0964 \\
\hline
\end{tabular}




\section{References}

(1) R. Draper, N.; Smith, H. Applied regression analysis, 3rd ed.; John Wiley \& Sons, Inc.: New York, NY, USA, 1998.

(2) Hyndman, R. J.; Koehler, A. B. Another look at measures of forecast accuracy. International Journal of Forecasting 2006, 22, 679-688.

(3) Jia, N.; Zhang, N. Multi-component optimisation for refinery hydrogen networks. Energy 2011, 36, 4663-4670. 